\title{
The Application of Bushing Tap Method in the Transformer Winding Deformation Test
}

\author{
Wang Wei, Jin Xin, Zhu Yuanda, Yin Yongfei, Zhang Su, Shi Xingcai, Jin Yi, Xu \\ Minghu, Zhao Hui, Liu Jun
}

The Technical Training Center, Liaoning Electric Power Company Limited, State Grid, China.

fushunpowersupply@163.com

Keywords: bushing taps method, bushing tap, oil-gas type transformer, winding deformation test

\begin{abstract}
Electric power industry standard DL/T911 - 2004 Frequency Response Analysis Method of Power Transformer Winding Deformation, it is definition of winding deformation: Under the action of mechanical force or electric force, the power transformer windings axial or radial size changes, usually it characterized by winding locally twisted, bulgin or shift characteristics. Under short-circuit current shocked or suffered a collision during transport transformer could happen for the winding deformation phenomenon, it will directly affect the safe operation of the transformer.
\end{abstract}

\section{The main cause of transformer winding deformation}

(1) Short-circuit fault current shock

Power transformer in the operation process, will inevitably suffer from all kinds of short-circuit fault current shock, especially the short-circuit fault in the transformer exports or the area near ,the huge short-circuit current shock will make transformer winding be subjected to the huge electric force(it is dozens of times to hundreds of times for the normal operation), and make the winding temperature rapidly. At higher temperatures, the mechanical strength of the wire becomes small,electric power is more easily to make the winding damage or deformation.

(2) In the transport, installation or cover lifting by the accidental collision

In the process of the transport, installation or cover lifting, power transformer may be subject to collision accident, bumps and vibrations, etc., Lead to the winding deformation.

(3) The winding withstand ability of short-circuit is not enough

When the winding appears short-circuit, due to it not withstands short-circuit current shock force and it occurs deformation. In recent years, for the country's $110 \mathrm{kV}$ and above power transformer accident statistical analysis shows that because of the winding withstand ability of short-circuit is not enough has become the most important internal reason for the power transformer accident, seriously affect the safe and reliable operation of the power transformer[1-3].

\section{The dangers of winding deformation}

The winding deformation is a great hidden danger for the safe operation of the power transformer. Many sets of transformer's actual test experience has shown that after winding deformation, the insulation test and the oil test are difficult to find, so the performance is the latent fault.

According to the evaluation of the twelfth session of CIGRE committee, many insulation fault of the transformer winding are caused by the initial mechanical damage of insulation. When transformer suffer in the short-circuit fault current shock and the winding product local deformation, even if not immediately damage, may also have left serious hidden danger.

\section{The research background of the bushing taps method}

The research of the bushing tap method and the application project in transformer winding 
deformation test ,mainly aim at the problem that the oil-gas type transformer cannot adopt the traditional method to have the frequency response method winding deformation test,it is following a new test method developed after the traditional frequency response method transformer winding test.

What is called the oil-gas type transformer, refers to the transformer high voltage leads not need through the capacitive bushing, but directly connected with the GIS combination electric appliance, through the GIS combined electric appliance in cable leads to transmission tower, if it suddens short-circuit faults in operation of the transformer, the need for have the winding deformation test to judge the transformer internal deformation degree, using the traditional method will not work.

The new research test method solves the above problems, and it is applicable to all power system installation of oil-immersed capacitive bushing and the voltage level of frequency response method winding deformation test. The operation of bushing tap method is simple, and mapping specification, solving the problem of the oil-gas type transformer winding deformation test, but also solving to have the conventional transformer winding deformation test in operation after the power outage without dismantling lead, the results reduce the power outage time, reduce the number of climbing, reduce workload, improve work efficiency, and ensure the reliability of power supply and people personal safety[4, 5].

\section{The test principle of the traditional method}

The test principle of the traditional method is shown in figure 1.In one end of the winding input sweep frequency voltage Vs, through digital recording equipment and at the same time test under different sweep frequency at two ends of the winding grounding voltage signal $\mathrm{Vi}(\mathrm{n})$ and $\mathrm{Vo}(\mathrm{n})$,after dealing with the corresponding to get the transfer function of the test transformer winding $H(n): H(n)=20 \log [\operatorname{Vo}(n) / V i(n)]$.

Before using the traditional frequency response test method, inspection personnel remove the all lead of the bushing tap, the test personnel climb to the high voltage bushing tap and respectively connect to excitation(input) and response (test).Several kinds of the common connection is as shown in Figure 1.
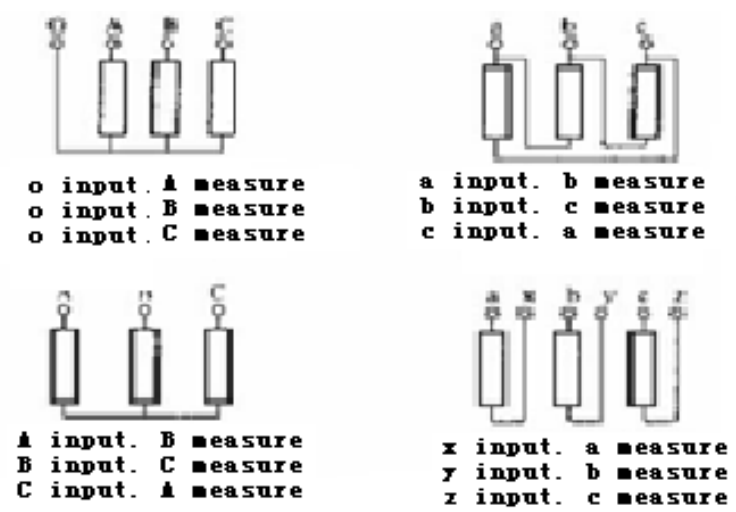

Figure 1 The several traditional wiring diagram

\section{The test principle of the bushing taps method}

What is called the bushing tap method is a new method that the input and the test is respectively connected to the small bushing of the capacitive bushing. The test method, mainly aim at the oil-gas type transformer (the high voltage bushing of the transformer is directly connected with GIS combination electric appliance) to have the transformer winding deformation test.

\section{The bushing taps method innovation and advantages}

(1) Before the traditional method for the frequency response method winding deformation test, 
it must be power outage for the test transformer, and then remove the lead between all high and low bushing, otherwise it can not be normal test. For the oil-gas type transformer to remove the lead is more difficult, because of the oil-gas type transformer without the lead head of the high voltage bushing (the high voltage winding through the GIS and cable to the high voltage tower), for the test it must remove the cable lead of the high voltage tower, while the use of the bushing tap method can easily solve the problem.

(2) The bushing tap is based on the principle of capacitance and inductance test, through the oil-gas type transformer's input or output signal of the lead capacitance bushing tap can be completed on the transformer winding deformation test work, for the conventional transformer can not to remove the lead and have the winding deformation test.The application of the results, not only can be reduced the fall dangerous of the height operation many times by the inspection personnel and the test personnel, but also solve the problem of the oil-gas type transformer winding deformation test, the test precision achieve the expected technical indicators, which can be used as the identification for the transformer fault in the future.

(3)For solving the problems of the oil-gas type transformer winding deformation test, improving the traditional transformer winding deformation test method. Advantages for improving the reliability of power supply are reducing the labor intensity; reducing the number of climbing; improving work efficiency.

\section{Application of the bushing taps method in the oil-gas type transformer test}

The oil-gas type transformer adopt the bushing tap method for the transformer winding deformation test, the actual connection diagram is as shown in Figure 2.

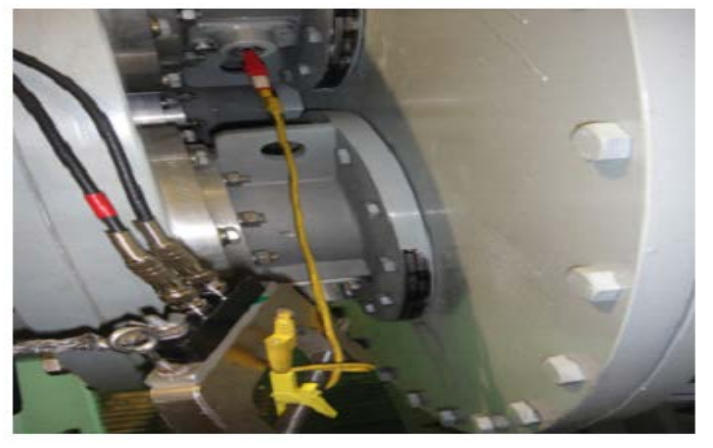

Figure 2 The bushing tap method connection's diagram

The oil-gas type transformer adopt the bushing tap method for the transformer winding deformation test, the actual test diagram is as shown in Figure 3.

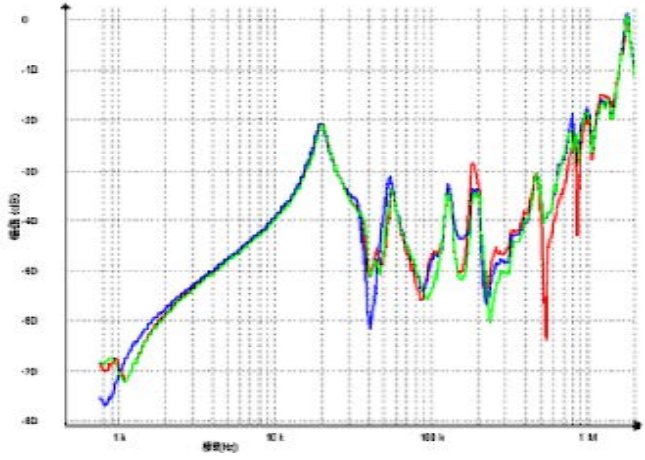

(a) The oil-gas type transformer high voltage

measurement diagram (the traditional method)

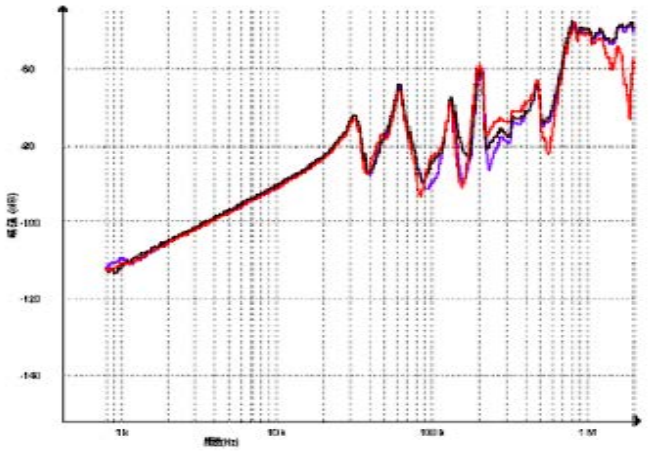

(b) The oil-gas type transformer high voltage measurement diagram (the bushing tap method)

Figure 3 The actual test diagram 


\section{The conclusions and suggestions}

(1)By comparing the traditional method test diagram and the bushing tap method test diagram for the $220 \mathrm{kV}$ power type transformer winding deformation, the amplitude and the phase angle test diagram can be used as one of the new method to judge the transformer winding deformation.

(2)By comparing the traditional method test diagram and the bushing tap method test diagram for the $66 \mathrm{kV}$ oil-gas type transformer winding deformation,the amplitude and the phase angle test diagram can be used as one of the new method to judge the oil-gas type transformer winding deformation.

(3)The bushing tap method is applicable to all power system installation of oil-immersed capacitive bushing and the voltage level of frequency response method winding deformation test.

(4)The bushing tap method solves the problem of the oil-gas type transformer winding deformation test, in the power outage power test ,it may not need to borrow special bushing and have the oil-gas type transformer winding deformation test, but also solves to have the conventional transformer winding deformation test in the operation after the power outage without removing the lead.

\section{Reference}

[1] Frequency Response Analysis Method of Power Transformer Winding Deformation. DL/T911, 2004

[2] Power Resistance Method For Detecting Transformer Winding Deformation Judge Guidelines. DL/T 1093, 2008

[3] Frequency Response Analysis Method of Power Transformer Winding Deformation. DL/T911, 2004.

[4] Chen Tianxiang, Wang Yinzhong. Electrical Test. Beijing: China power press, 2010

[5] Three live working procedures. China Electric Power Press, 2003. 